\title{
Finite Element Model Correlation of an Investment Casting Process ${ }^{\ddagger}$
}

\author{
ANGLADA, Eva ${ }^{1, a^{*}}$, MELÉNDEZ, Antton ${ }^{1, b}$, MAESTRO, Laura ${ }^{2, c}$ \\ and DOMÍNGUEZ, Ignacio ${ }^{2, d}$ \\ ${ }^{1}$ TECNALIA. Industry and Transport Division, Mikeletegi Pasealekua 2, Donostia - San Sebastián \\ E-20009, Spain \\ ${ }^{2}$ Precicast Bilbao. El Carmen s/n, Barakaldo E-48901, Spain \\ a eva.anglada@tecnalia.com, ${ }^{\mathrm{b}}$ antton.melendez@tecnalia.com, ${ }^{\mathrm{c}}$ laura.maestro@pcb.es, \\ dignacio.dominguez@pcb.es
}

Keywords: Numerical simulation; inverse problem; correlation; finite elements; investment casting; superalloy.

\begin{abstract}
The achievement of reliable simulations, in the case of complex processes as is the investment casting, is not a trivial task. Their accuracy is significantly related with the knowledge of the material properties and boundary conditions involved, but the estimation of these values usually is highly complex. One helpful option to try to avoid these difficulties is the use of inverse modelling techniques, where experimental temperature measurements are used as base to correlate the simulation models.

The research presented hereafter corresponds to the correlation of a finite element model of the investment casting process of two nickel base superalloys, Hastelloy $\mathrm{X}$ and Inconel 718. The simulation model has been developed in a commercial software focused specifically on metal casting simulation. The experimental measurements used as base for the adjustment, have been performed at industrial facilities. The methodology employed combines the use of an automatic tool for model correlation with the manual adjustment guided by the researchers.

Results obtained present a good agreement between simulation and experimental measurements, according to the industrial necessities. The model obtained is valid for the two studied cases with the only difference of the alloy material properties. The values obtained for the adjusted parameters in both cases are reasonable compared with bibliographic values. These two circumstances suggest that the obtained correlation is appropriate and no overfitting problems exist on it.
\end{abstract}

\section{Introduction}

Numerical simulation has become a useful technique to help in the improvement of many manufacturing methods, among which are those related with the foundry industry. Nevertheless, the obtaining of reliable simulations is not a trivial task, especially in the case of complex processes as is the case of the investment casting.

Different authors, as Bonollo and Odorizzi in [1] or the ASM International Handbook Committee in [2], have stated the importance of the application of the appropriate boundary conditions and material properties, in the performance of accurate simulations.

The correct estimation of some boundary conditions, for example the heat transfer coefficients between the different materials, results highly complex. Moreover, the characterization of the material properties at the high temperatures involved in the casting process is not easy. The classical solution is to resort to data from bibliography, but results not always are as good as it would be desirable.

One helpful option to try to avoid these difficulties is the model correlation by means of inverse modelling. Inverse modelling techniques make possible to estimate the value of some parameters of

\footnotetext{
* A previous version of this paper was presented in the $5^{\text {th }}$ Manufacturing Engineering Society International Conference and appears in its proceedings, see bibliographic reference [10].
} 
the model, taking into account the direct experimental measurements performed over other related variables. In the case of the investment casting simulation, instead of the direct characterization of the material properties or boundary conditions, the thermal histories in some specific points of the part and mold are recorded during the manufacturing process. These thermal histories are used as base and the adjustment progress in an iterative process, where some model parameters are modified, the simulation is run and results are checked. In this way, the process continues until the simulated cooling curves fit appropriately with those registered experimentally.

The main drawback of this type of approach is that sometimes could lead to an overfitting problem. The overfitting occurs when the model represents very well the experimental case used to correlate it but it works wrong for other similar cases. That is, the model does not generalize well. In many cases, as Marwala says in [3], this situation takes place when the finite element model has been too tuned to reflect the measured data but the fitting has been done at expense of the physics, for example using material properties values too far from the real ones. This situation is more frequent when the model correlation is tackled by means of automatic methods, usually based on computational intelligence techniques. The reason is that this type of techniques could lead easier to values far away from the physics than in the case the correlation is manually guided by the researchers. Of course, the advantage of the automatic techniques is the speed of the calculations.

The model correlation presented hereafter has been achieved by means of inverse modelling. The manual modification of the involved parameters based on the researchers experience has been combined with an automatic tool based on the method presented by Rappaz et al. in [4], which is included in the simulation software employed [5].

A wide number of papers focused on the application of inverse modelling to metal casting simulation exists but most of them are focused on the determination of the heat transfer coefficient between the mold and the alloy, as occurs in bibliographic references [6-9].

The work presented here deals with the adjustment of the whole simulation model and not only with the heat transfer coefficients. Moreover the experimental data have been registered during the industrial process, where conditions are not as controlled as at laboratory. The prototypes have been manufactured at the foundry facilities following the industrial standards and procedures usual for some components of aeronautical turbines. The cases of study are the investment casting processes of two different nickel base superalloys, Hastelloy X and Inconel 718, poured in vacuum conditions.

\section{Methodology}

Experimental data acquisition. The experimental data acquisition consists in the recording of the process parameters and especially of the temperature evolution during the investment casting procedure in specific points of the prototypes used. These prototypes have been specifically designed for this task. The only difference between they and the typical industrial parts is the geometry, which is much simpler in the prototypes in order to make easier the data acquisition and to reduce the calculation times. The prototype geometry corresponds to a cylinder $43 \mathrm{~mm}$ diameter and $235 \mathrm{~mm}$ length with a simple feeding system, as can be observed in Fig. 1.

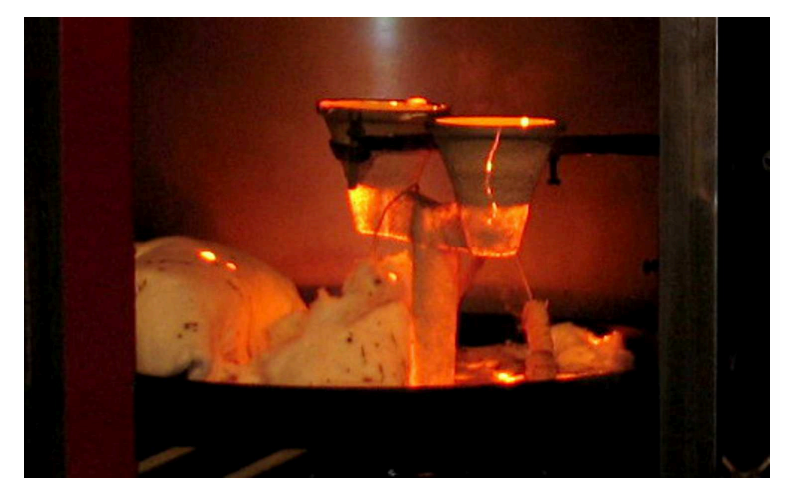

Fig. 1. Photograph of one prototype into the vaccum furnace at the end of pouring process. 
The thickness of the ceramic shell mold, mainly aluminium silicate, varies between 6 and $9 \mathrm{~mm}$ depending on the different areas of each mold. Relating to the process parameters, the mold preheating temperature varies between $1050^{\circ} \mathrm{C}$ and $1150^{\circ} \mathrm{C}$ and the pouring temperature between $1480^{\circ} \mathrm{C}$ and $1564^{\circ} \mathrm{C}$. Time since the mold extraction from the preheating furnace until alloy pouring is between 120 and 165 seconds.

Temperatures have been measured by means of thermocouples inserted into the ceramic shell molds and into the metallic cast parts. These measurements, after the treatment of the raw values, are shown in Fig. 2 for Hastelloy X alloy and in Fig. 3 for Inconel 718 alloy. Both graphs include also the curves corresponding to the average temperatures calculated for the alloy and the mold.

The differences registered between the behavior of Hastelloy X and Inconel 718 can be observed in Fig. 4. As can be noted the main difference relies on the solidification temperatures and on the cooling rates. The shrinkage defects have been evaluated in location and magnitude cutting the cast prototypes appropriately.

It is needed to mention that the maximum temperatures registered does not match the pouring temperatures. The reason seems to be related with the thermocouple thermal inertia.

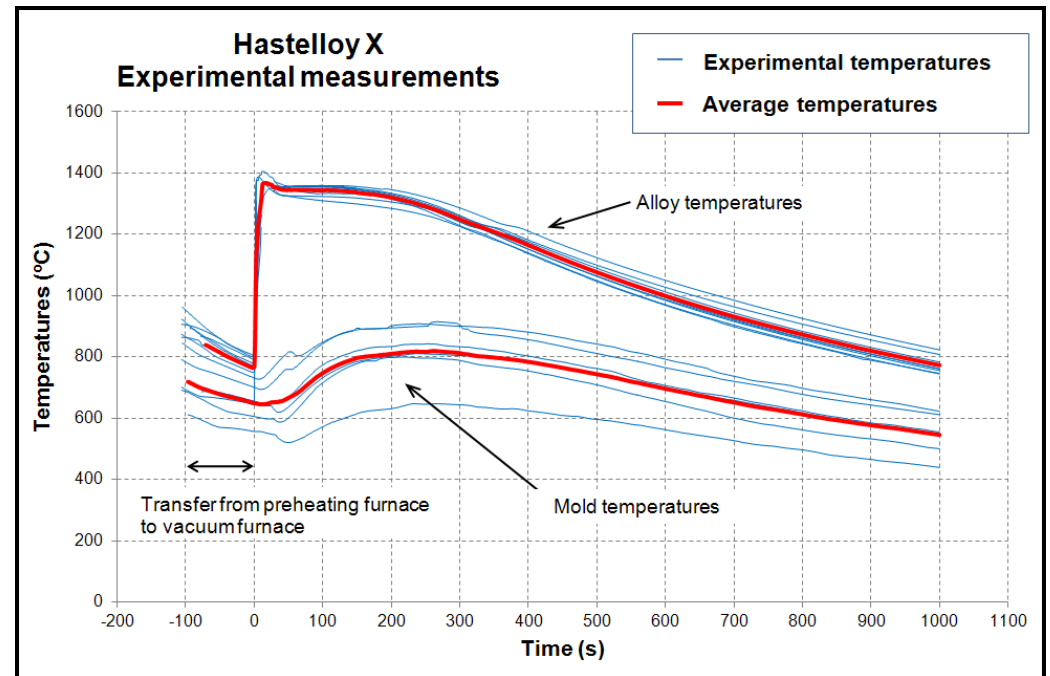

Fig. 2. Temperature measurements and average values for Hastelloy $\mathrm{X}$ alloy and mold.

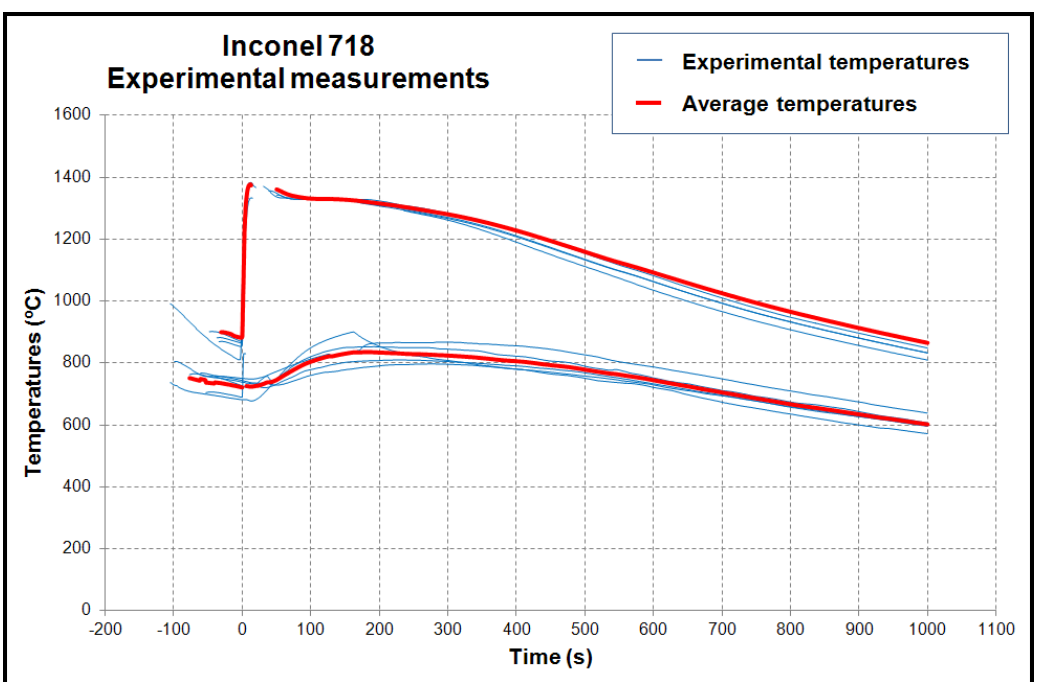

Fig. 3. Temperature measurements and average values for Inconel 718 alloy and mold. 


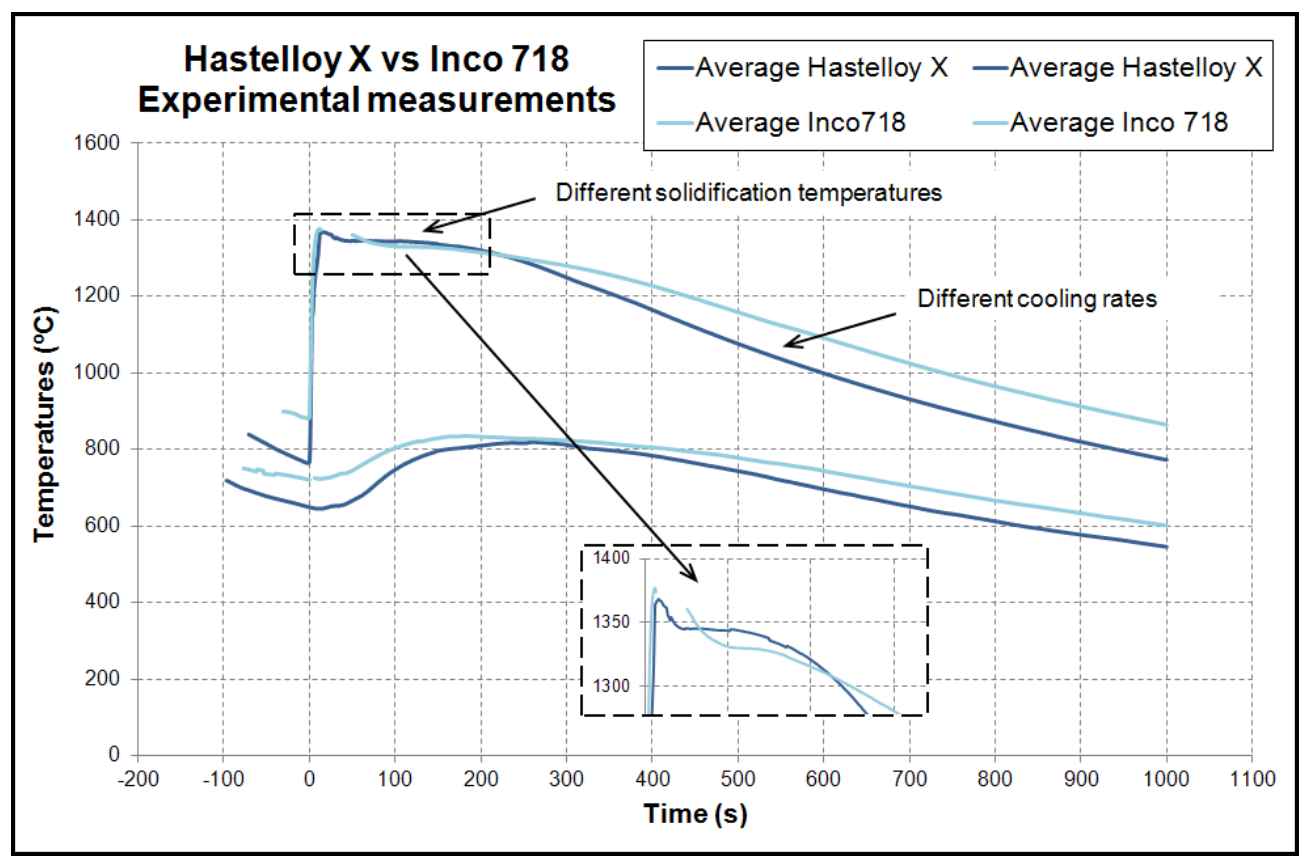

Fig. 4. Comparison between Hastelloy X and Inconel 718.

Correlation of the simulation models with experimental data. The variables of the simulation models that have been subjected to the correlation process are the material properties, the heat transfer coefficient between the different materials and the boundary conditions needed to reproduce the pouring and the ambient conditions.

The model correlation of the Hastelloy $X$ case was performed in first place. The material properties of the ceramic shell mold and the Hastelloy X alloy were adjusted together with a set of heat transfer coefficients and boundary conditions. A more detailed explanation about the methodology followed to perform this adjustment of the simulation model to the experimental data can be found in a previous version of this paper, see [10].

Once reached this first adjustment, the model fitting of the Inconel 718 case was tackled. As the only difference between both cases is the alloy, only its material properties were subjected to the correlation process. The rest of values, that is, the material properties of the mold, the heat transfer coefficients and the boundary conditions, were those obtained for the Hastelloy X case adjustment. Only minor modifications in the boundary conditions, as the pouring temperature or the transfer time, were performed to fulfill the experimental data corresponding to this case of study.

\section{Results and Discussion}

Fig. 5 shows the results obtained for the Hastelloy X case. As can be observed, the simulation results corresponding to the preliminary model used as base for correlation do not fit appropriately with the average curves obtained from the experimental temperature measurements. However, once the model adjustment has been reached, simulation results are clearly improved and the cooling curves fit much better with the experimental data.

The values obtained for the material properties involved and also for the rest of parameters of the simulation are reasonable compared with the bibliographic values. More information about these values is included in a previous version of this paper [10].

Fig. 6 shows the results obtained for the Inconel 718 case. In this case the preliminary model used as base includes the values previously adjusted in the Hastelloy $\mathrm{X}$ case, excepting the alloy material properties. As can be observed, once the Inconel 718 material properties has been adjusted, simulation results fit well the experimental data. The values obtained for the Inconel 718 material properties are reasonable compared with bibliographic data as well. 
With regard to the shrinkage defects, results predicted by the simulation models once adjusted were satisfactory for the industrial necessities in both cases, Hastelloy X and Inconel 718.

The reaching of an adjustment with reasonable material properties for the second case, Inconel 718 , based on the model previously adjusted for the Hastelloy X case, suggest that the adjustments obtained are adequate and no overfitting problems exist on them. Otherwise, if the first adjusted model would be affected by overfitting, is improbable that the second adjustment would be reached with reasonable material properties.

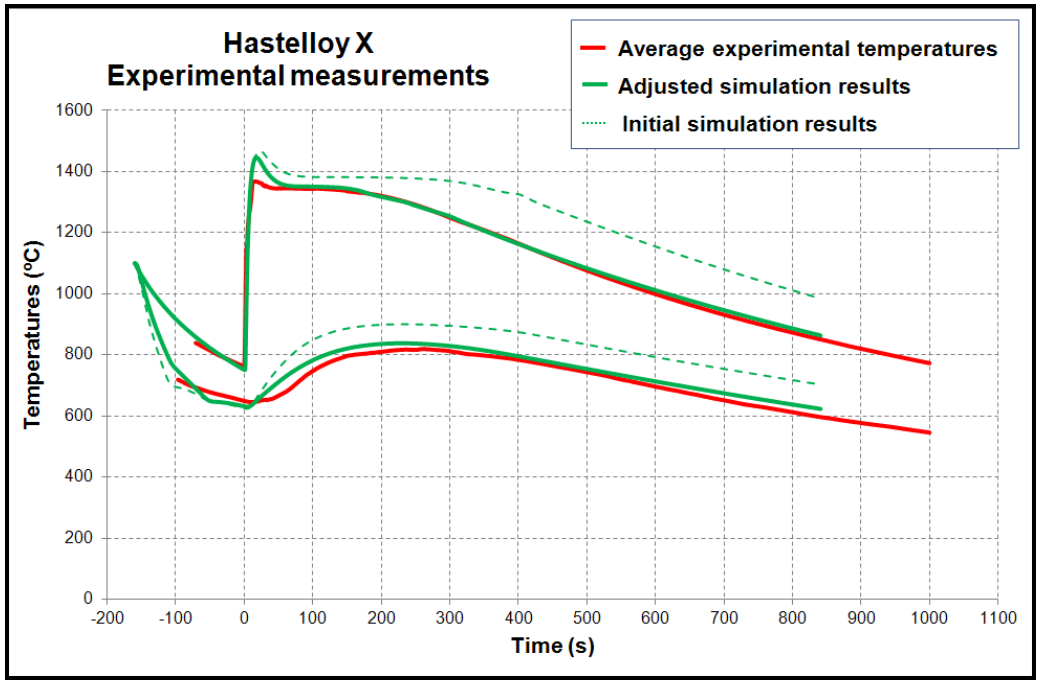

Fig. 5. Experimental average cooling curves vs simulation results for Hastelloy X case.

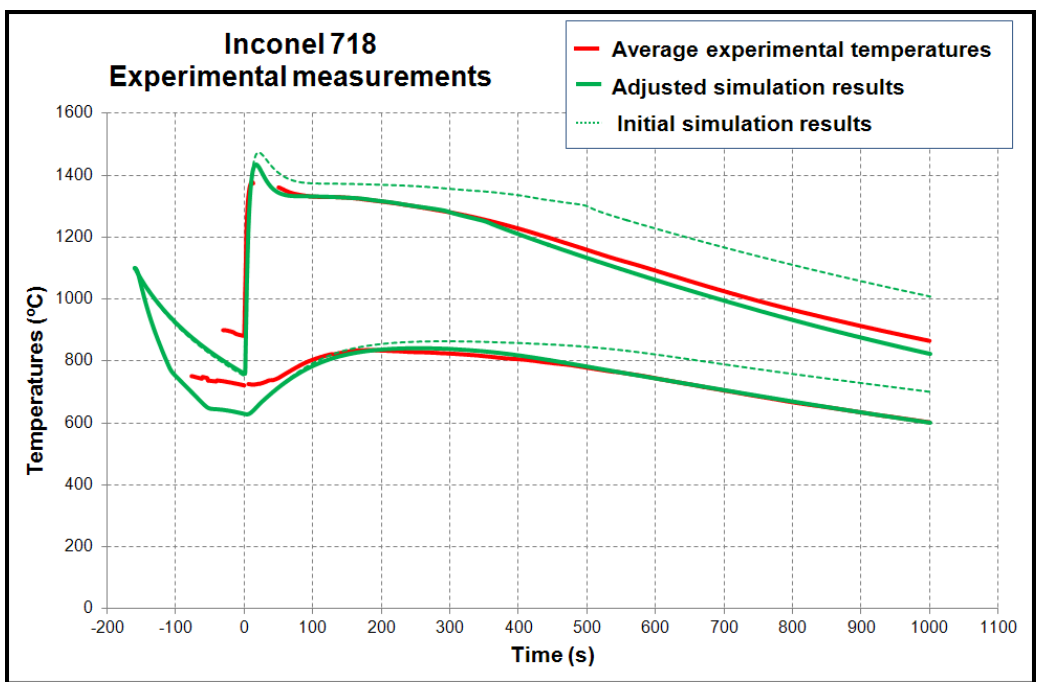

Fig. 6. Experimental average cooling curves vs simulation results for Inconel 718 case.

\section{Conclusions}

The finite element model correlation of the investment casting process of two different nickel base superalloys, Hastelloy X and Inconel 718, has been obtained. In both cases simulation results fit according to the industrial necessities the experimental data registered at foundry. The adjustment has been achieved by means of inverse modelling, based on the cooling curves measured experimentally at the industrial plant.

The adjusted model obtained is valid for the two similar, but different, investment casting cases. The only difference between both simulation models is the alloy material properties. Moreover, the values obtained for the adjusted parameters in both cases are reasonable compared with bibliographic values. These two circumstances suggest that the adjustment obtained is adequate and 
no overfitting problems exist on it. The simulation model comprises the whole casting process, since the mold extraction from preheating furnace to the final cooling after the pouring.

The contribution of this work is to provide new data to collaborate with the validation of this technique for model adjustments, based on data registered at industrial level. At least, for the case of the investment casting simulation.

\section{Acknowledgements}

This work has been developed as part of two different projects: GALDATEK and EUSKESTUR. Funded respectively by the INNOTEK and the ETORGAI programs of the Basque Government (Department of Industry and Innovation).

\section{References}

[1] F. Bonollo, S. Odorizzi, Numerical simulation of foundry process, Servizi Grafici Editoriali, Padova, 2001.

[2] ASM International Handbook Committee, ASM Handbook, Metals Process Simulation, ASM International, Ohio, 2010.

[3] T. Marwala, Finite Element Model Updating Using Computational Intelligence Techniques: Applications to Structural Dynamics, Springer, Heidelberg, 2010.

[4] M. Rappaz, J.L. Desbiolles, J.M. Drezet, C.A. Gandin, A. Jacot, P. Thévoz, Application of inverse methods to the estimation of Bound Cond and properties, in: M. Cross, J.E. Campbell (Eds.), Modelling of Casting, Welding and Advanced Solidification Processes VII, TMS, London, 1995, pp. 449-457.

[5] ESI Group, ProCAST, [Computer program].

[6] Y. Dong, K. Bu, Y. Dou, D. Zhang, Determination of interfacial heat-transfer coefficient during investment-casting process of single-crystal blades, Journal of Materials Processing Technology 211 (2011) 2123-2131.

[7] J.M. Drezet, M. Rappaz, G.U. Grün, M. Gremaud, Determination of thermophysical properties and boundary conditions of direct chill-cast aluminum alloys using inverse methods, Metallurgical and Materials Transactions A 31 A (2000) 1627-1634.

[8] H. Jin, J. Li, D. Pan, Application of inverse method to estimation of boundary conditions during investment casting simulation, Acta Metallurgica Sinica (English Letters) 22 (2009) 429-434.

[9] D. O'Mahoney, D.J. Browne, Use of experiment and an inverse method to study interface heat transfer during solidification in the investment casting process, Experimental Thermal and Fluid Science 22 (2000) 111-122.

[10] E. Anglada, A. Meléndez, L. Maestro, I. Domínguez, Adjustment of Numerical Simulation Model to the Investment Casting Process, in: J.J. Aguilar-Martín, J.A. Yagüe-Fabra (Eds.), The Manufacturing Engineering Society International Conference, MESIC 2013, Procedia Engineering, 2013, pp. 75-83. 